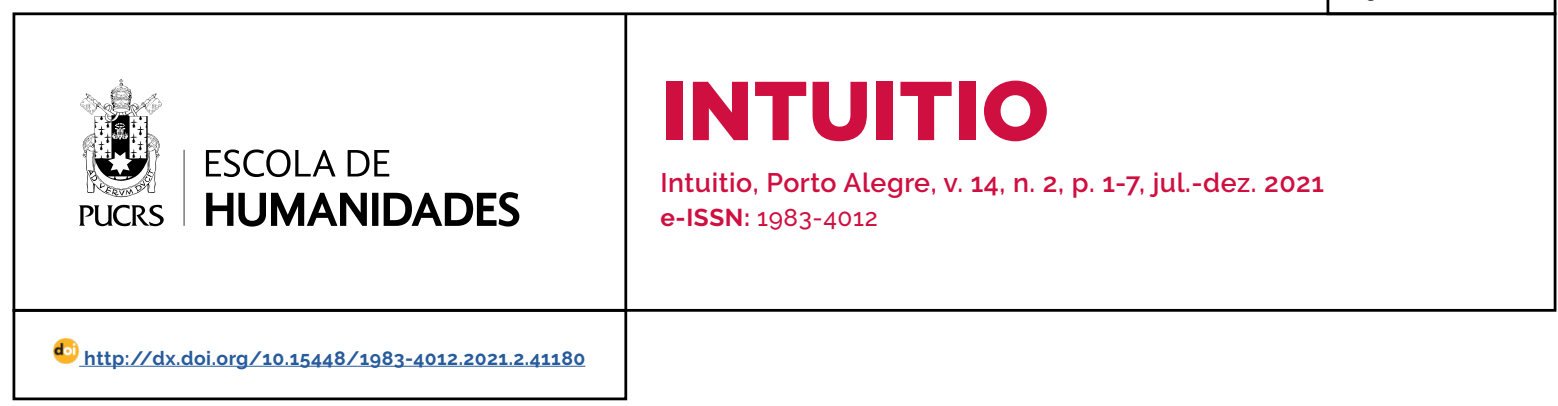

SEÇÃO: ARTIGO

\title{
Sobre o Estado ideal e a religião na obra As Leis de Platão
}

On the ideal state and religion in Plato's laws

\section{Claudio De Cicco ${ }^{1}$}

orcid.org/0000-0001-8105-4681

claudiodecicco@uol.com.br

\section{Alvaro de Azevedo \\ Gonzaga ${ }^{1}$}

orcid.orgy0000-0002-4051-0748

alvarofilosofia@hotmail.combr

\author{
Felipe Labruna ${ }^{1}$ \\ orcid.org/0000-0003-3844-3301 \\ fe.labruna@gmail.com
}

Enviado em: 24/06/2021.

Aprovado em: 23/07/2021.

Publicado em: 21/01/2022.

\section{(c) (1)}

Artigo está licenciado sob forma de uma licença Creative Commons Atribuição 4.0 Internacional.
Resumo: As Leis de Platão apresentam-se como uma coleção de comandos juridicos detalhados que trata sobre diversos temas, entre eles a composição do Estado ideal em uma cidade utópica chamada Magnésia e a imprescindibilidade na crença nas divindades. A preocupação de Platão com as crenças religiosas está associada à necessidade de manutenção da ordem moral e política. Para o filósofo, uma cidade em que seus habitantes duvidam da existência de seres superiores capazes de punir os impios será sempre vitima do caos moral. A crença nos deuses foi então defendida como elemento fundamental para o bem da pólis e a excelência dos cidadãos e, neste sentido, Platão tentou articular as dimensões humana e divina.

Palavras-chave: As leis. Divindades. Estado. Platão. Religião.

Abstract: Plato's Laws are presented as a collection of detailed legal commands dealing with various topics, including the composition of the ideal state in a utopian city called Magnesia and the indispensability of belief in deities. Plato's concern with religious beliefs is associated with the need to maintain the moral and political order. For the philosopher, a city in which its inhabitants doubt the existence of superior beings capable of punishing the wicked will always be a victim of moral chaos. Belief in the gods was then defended as a fundamental element for the good of the polis and the excellence of its citizens and, in this sense, Plato tried to articulate the human and divine dimensions.

Keywords: Deities. Laws. Plato. Religion. State.

\section{Introdução}

A obra As Leis é, como é sabido, o derradeiro e mais extenso diálogo da produção platônica, o material em que Platão nos oferece a resenha final e mais laboriosa de seu raciocínio político. Sem embargo, esse texto, por longo periodo, foi menosprezado pela historiografia filosófica tradicional, sendo entendido em muitas ocasiões como uma obra marginal e de menor relevância no conjunto dos frutos platônicos. De fato, possuindo uma coleção de comandos juridicos detalhados, debruçando-se sobre temas aparentemente inócuos como a razão educacional dos banquetes, o regulamento do matrimônio, o arranjo da terra, os negócios comerciais e o direito à herança, As Leis foram encaradas, desde o período da Antiguidade, como um feito com reduzido teor de filosofia e pouca profundidade. Tal situação dificultou muito a maneira com que essa obra foi recepcionada pelos leitores. Para diversos apreciadores, em oposição à audácia de cunho 
teórico e especulativo presente na obra A República, As Leis não eram mais que um mero roteiro de legislações trivial, cansativo e até mesmo supérfluo, tido então como mero resultado da imaginação de um idoso frustrado e abandonado, de tal forma que o genuíno Platão poderia ser encontrado em outros célebres escritos. Entretanto, felizmente na atualidade notamos que o contexto evidentemente se alterou e que a maior parte dos críticos reconhece a relevância essencial de As Leis para que haja o entendimento da ponderação elaborada por Platão (OLIVEIRA, 2007, p. 336).

Platão estreou uma nova forma de expressão sobre o tema da divindade. Essa nova espécie de fala a respeito dos deuses destinou-se a assentar o governo do corpo social e seu enunciado argumentativo caminha por um eixo racional. A concatenação de seus componentes se dá, pautado no método matemático, conforme regramento que possui a meta de tornar imprescindivel sua conclusão.

Todavia, Platão não renega os consagrados mitos a que se refere em seu texto. Foram adaptados mitos tradicionais e há momentos inclusive em que se criam novos mitos em razão das contingências. Tal fato se deve basicamente por alguns motivos. Por um ângulo, verifica-se que não é viável a expressão, a não ser em termos míticos sobre certos referenciais, isto é, sobre tudo o que se refere à alma e a tempos remotos e que, em razão de suas naturezas, encontram-se inalcançáveis tanto para as sensações perceptivas quanto para a racionalidade. A noção de que o espírito teve sua essência dissociada da matéria corpórea, momento esse em que absorve certo senso epistêmico que ele deve rememorar em suas existências posteriores, está declaradamente associada às tradições de feição religiosa nas obras Ménon, Fédon e também no Banquete.

A noção segundo a qual o agir antecede o teor de uma retribuição está bem calcada em diversos mitos escatológicos. Em síntese, a concepção de que as divindades se encarnam em vários corpos de pessoas ou de animais está explícita no Fedro e no Timeu. Além disso, tudo que aborda o inteligivel está ligado à mítica através de crenças sobre a alma. E é igualmente dessa forma no que diz respeito à criação do mundo sensivel, como se pode verificar no Timeu. Como consequência, a mitologia estabelece um espaço fértil em que diversas questões filosóficas fincam seus próprios alicerces: é um depósito de princípios, valores e de premissas (BRISSON, 2003, p. 28).

\section{Sobre como os diálogos se apresentam}

A tentativa neófita de compreensão das obras platônicas tende a pautar-se, em primeira ordem, na confrontação dos diálogos expostos como se monólogos fossem. Em outros termos, encaram-se basicamente todas as definições e linhas de raciocínio elaboradas nos textos como "pensamentos de Platão", sem que se repare que há diversos personagens em cena e que esses podem estar representando condutas e posicionamentos que o filósofo, em um discurso solitário, nunca defenderia. Se esse tipo de interpretação for levado adiante, os leitores que intentarem na busca pela coerência doutrinária dos escritos platônicos terão grandes adversidades para alcançá-la.

O que é preciso ser feito, então, é escolher certos diálogos que podem ser chamados de "canônicos" ou "convencionais" e procurar submeter as presumidas exegeses desses escritos singulares a todas as demais hipóteses apresentadas nos outros textos. Além disso, há os que se satisfazem com a apreciação de cada diálogo separadamente, sem consideração com a totalidade da obra. Tal modo de agir apresenta equívoco assemelhado ao que fora indicado por $\mathrm{Hegel}^{2}$ ao tratar sobre as leituras que alguns de seus pares realizavam de Platão: ao invés de colocar em funcionamento um método farto de especulação que buscas se envolver a completude dos diálogos, esses intérpretes, encabulados em meio à heterogeneidade e à variedade, acabam meramente amontoando alguns conceitos enquanto ofuscam orientações reflexivas (MOURA, 1998, p. 202).

\footnotetext{
2 Apud BENOIT, Alcides Hector Rodriguez. A dialética hegeliana como superação da dialética platônica. Idéias, Campinas, v. 1, n 1, 1994. p. 95
} 
Os estudiosos contemporâneos puderam desenvolver uma definição ainda mais drástica a respeito das interações entre a prática filosófica e a política no campo platonista, isto é, a ideia de que o ato filosófico platônico era uma ação política não somente em razão de seus temas, mas igualmente em razão de seu próprio nascimento ou origem, afinal, no fundo, era oriunda de uma intenção política infrutifera, ou, como fora salientado por Auguste Diès em uma afirmação muitas vezes transcrita, foi fruto "de uma ação política obstruida" (DIĖS, 1947, tomo VII, p. V). O principal atributo inerente ao texto da obra Carta VII que, para seus críticos, atestariam e justificariam este tipo de interpretação é essencialmente que Platão, neste documento, inicia comunicando o leitor que, como todo aristocrata de Atenas de seu tempo, alimentara na idade tenra o anseio de se debruçar sobre as questões da pólis.

Entretanto, Platão transmite logo a seguir que os enfadonhos acontecimentos históricos pelas quais enfrentara a cidade de Atenas, inicialmente com a regência despótica e impiedosa dos trinta tiranos e posteriormente com os percalços da democracia, cujos tribunais sentenciaram à morte seu doutrinador e mentor Sócrates, o trouxeram à amargurada conclusão de que a política de sua era estava infalivelmente subjugada e deteriorada pela postura de governantes injustos. Desolado com a situação do ambiente, Platão acaba, por conseguinte, confessando que foi levado imperiosamente a bendizer a reta filosofia, enxergando nela a única maneira de se alcançar a justiça em meio à corrupção da pólis. Assim, para os estudiosos de Platão, tais informações textuais são mais do que suficientes para que não haja quaisquer incertezas a respeito do fato de que a filosofia platônica foi, desde o começo, uma filosofia dotada essencialmente de cunho político. Tal assertiva não se deve somente pelo seu teor ou pelos seus assuntos, mas principalmente em razão de sua origem e nascimento (OLIVEIRA, 2006).

\section{A estrutura do Estado ideal}

A estrutura do Estado, para uma cidade utópica denominada Magnésia, é um dos temas que
Platão apresentou com maior cuidado e profundidade em seus diálogos não As Leis. Nesse sentido, não só estão presentes os três poderes públicos constituindo o Estado, mas de maneira independentemente existe uma força pública, que inclui a defesa da organização política da sociedade, além de um regime de polícia dividido em guarda rural, guarda do mercado e guarda urbana. Platão genericamente chama todas essas unidades de magistraturas do Estado.

A primeira coisa a se notar é que essas magistraturas estão divididas em órgãos deliberativos, órgãos executivos, aparelhos judiciais e órgãos de controle. Os órgãos deliberativos oficiais estatais são a Assembleia e o Conselho, embora fossem comuns diversos ajuntamentos onde se reuniam cidadãos. As magistraturas executivas são aquelas relacionadas à familia, à educação, às autoridades religiosas e também no que diz respeito à manutenção da ordem pública, utilizando-se do exército e da polícia. Quando se trata de Justiça, existem os tribunais e os juízes. No entanto, é necessário esclarecer que no As Leis Platão não fizera um estudo meticuloso sobre todas as magistraturas, uma vez que algumas delas só são enunciadas nos seus demais diálogos sobre ciência política (BALLÉN, 2007, p. 46).

Na obra As Leis, o regime de governo sugerido para a colônia em Magnésia abrange diversos tipos de magistratura (seja ela juridica, pedagógica, militar, religiosa etc.) e uma composição política que harmoniza elementos da democracia e da monarquia, que seriam, para Platão, a liberdade e a amizade, acompanhadas de sabedoria. A razão disso é que para ele o excesso de liberdade não levaria a uma condição de soberania de si e de um povo. Os elementos intelectuais não foram desprezados nesse modelo de regência, afinal a pólis deveria ser guiada pela medida, pela inteligência e pela virtude. Nesse sentido, aqueles contemplados pela educação filosófica (Conselho Noturno) teriam uma relevância essencial: associados à alma ou ao intelecto da pólis, por serem pautados pelo discernimento e pela opinião verdadeira. Assim, detínhamos melhores requisitos para elaborar leis contempladas por 
essa sabedoria e também para reformá-las. Para o conjunto da cidade, referidas leis tinham cunho educacional e de persuasão, sendo formuladas por legisladores-filósofos e funcionavam como a reta opinião. A ação ético-política dos cidadãos, oriunda da educação da alma por esse sistema de valores, era então hábil para harmonizar a alma como um todo, devendo então ser uma atuação justa. A sabedoria e os diálogos filosóficos seriam igualmente utilizados com a finalidade de instrução de integrantes mais jovens do próprio Conselho, os impios e os próximos governantes (REIS, 2007).

A Assembleia é o órgão supremo do Estado e é composta por todos os cidadãos que pertenceram ou fazem parte do exército. Todos aqueles que pertencem à cavalaria ou à infantaria ou que participaram da guerra assim que o podiam em razão da idade devem participar na eleição dos magistrados A eleição deve ocorrer no templo que a cidade considerar mais importante. Deveria ser depositado o voto de cada um no altar do deus, escrevendo em uma lápide o patronímico do candidato, da tribo e do distrito a que pertence, colocando também seu nome ao lado dele, seguindo o mesmo procedimento.

As Leis não especifica a periodicidade das reuniões da Assembleia e suas funções são de natureza múltipla: eleitoral, judicial, legislativa e política, como se depreende do estudo dos livros VI e VIII da obra. Quanto ao sistema de votação nas eleições para membros da magistratura, pode dizer-se que se tratava de um sistema misto ou complexo, visto que para várias organizações a Assembleia fazia a eleição e seguidamente o procedimento de sorteio, o que tornava o sistema mais democrático. Em relação às funções, a Assembleia deveria abrir e encerrar os processos por crimes contra o interesse público. Nas denúncias de crimes contra o interesse público era necessário, antes de tudo, a participação da multidão das sentenças, pois quando alguém agride a cidade, os atingidos são todos (PLATÃO, 2021, livros VI e VIII).

Depois da Assembleia, o Conselho, tratado no livro VIII da obra, é o maior órgão que Platão propõe para o Estado da Magnésia: 360 membros no total, a uma taxa de 90 indivíduos para cada uma das quatro classes sociais em que o próprio filósofo ateniense dividiu a sociedade. A eleição seria mista ou complexa, afinal de cada uma das classes sociais deveriam ser eleitos pelos cidadãos 180 individuos e, dentre estes, 90 seriam sorteados. Essa é a origem do governo misto, afinal a eleição sendo feita desta forma manteria para Platão um ponto equidistante da ordem política monárquica e democrática, no meio do qual o sistema político devia estar sempre.

As funções do Conselho não eram desempenhadas pelo órgão como um todo, mas por meio das comissões nas quais era dividido. As comissões, que eram doze, eram chamadas de pritania e seus integrantes exerciam suas funções de governo em uma comissão por mês, tendo o resto do tempo para dedicarem-se a seus negócios particulares. Para Platão, se fazia necessária a permissão para que a maioria dos vereadores se dedicasse aos seus assuntos privados e administrasse suas próprias finanças, ao passo que deveriam gerir seu tempo para que desempenhassem suas atividades nas comissões (BALLÉN, 2007, p. 49-50).

\section{A religião e as divindades}

Pode-se dizer que a preocupação de Platão com as crenças religiosas está subordinada justamente à manutenção da ordem moral e política. Isso porque ele considera que uma cidade em que seus habitantes duvidam da existência de seres superiores capazes de punir os ímpios será sempre vítima do caos moral. Então, a crença nos deuses foi defendida como elemento fundamental para o bem da pólis e a excelência dos cidadãos. Para Platão, o medo do castigo nesta e em outras vidas é absolutamente necessário para manter a ordem política. A única restrição às paixões vis é o terror que a justiça divina inspira em todos. É necessário conciliar a ordem social da República que é baseada em educação, com a lei e esta é baseada principalmente no medo. Neste sentido, o Livro X de As Leis se inicia estabelecendo uma regra de validade universal para 
crimes contra a propriedade: ninguém poderia levar ou carregar nada estrangeiro, nem usar nada dos vizinhos se não tiver obtido a permissão do proprietário.

Platão defende que quem vive com medo da justiça divina nunca cometerá nenhum crime. Então, os que costumam cometê-los são os que pensam que os deuses não existem, ou que, se existem, ou não se interessam pelos assuntos humanos ou podem ser seduzidos por orações e oferendas. É necessário, portanto, argumentar a favor do fato de que os deuses existem, distribuem recompensas e punições, e não se deixam subornar pelos homens. O primeiro argumento apresentado a favor da existência dos deuses é olhar para o céu: o sol, a lua e as outras estrelas são seres divinos, movem-se por si mesmas de maneira ordenada e são imortais. Então diz Platão que a alma é anterior e precede tudo o que é material. Isso na tradição aristotélica leva o nome de "argumento do primeiro motor": visto que o material é incapaz de se mover, nós temos que supor um primeiro princípio espiritual capaz de engendrar movimento em si mesmo e em outras coisas (NADDAF, 1980, p. 601-602).

É exposto que uma variedade de almas governam todos os objetos na Terra e também nos céus. Somente a uma alma boa se pode atribuir a ordem matemática, plena de virtude e beleza, dos céus, afinal se o regente fosse outro, os planetas iriam daqui para lá de forma louca e desordenada. É considerado então que essa alma, ou o faz de dentro, como nossa alma localizada dentro do corpo, ou o faz de fora, e tendo obtido um corpo de fogo ou de um certo tipo de ar, empurra o resto do Universo, sendo então imanente ou transcendente. Defende-se no texto a importância do trato àqueles que, mesmo admitindo sua existência, acreditam que não se importam com os assuntos humanos.

Segundo Platão, a origem dessa crença seria uma variante do que é conhecido como o "problema do mal". As pessoas viam que os ímpios tomam o poder e são felizes, mas não querem culpar deuses perfeitos por isso, então concluiam que os deuses desprezam os assuntos huma- nos e não se importam com eles. Platão então responde a essa objeção de uma forma que o cristianismo posterior aproveitaria: os deuses só podem ser responsáveis pelo que há de melhor porque são completamente bons e virtuosos e não é possível atribuir preguiça ou indiferença aos assuntos humanos. É verdade que, quando o destino não nos é favorável, atribuímos a falta de sentido a todo o Universo, sem reconhecer nossa ignorância quanto ao que convém ao todo (PLATÃO, 2021, livro X).

Os que acreditavam que o mal nunca seria alcançado pela justiça divina deveriam compreender que a justiça nunca lhes negligenciaria, estando então todos fadados a pagar a punição correspondente por suas ações. Entretanto, aos que pensavam que deuses existiam, mas que eram seduzidos por presentes e orações, tal crença deveria ser afastada, porque isso seria transformar os deuses, admiráveis e perfeitos guardiões do movimento do Universo, em vulgares personagens subornados pelo vinho. Apresentam-se então dois tipos de impiedade para aqueles que acreditavam em deuses: um tipo seria o sábio que não acreditava em deuses, mas desenvolvia um caráter justo, já o outro afirmaria que as coisas estavam abandonadas aos deuses e corrompia sua alma cedendo aos prazeres. A mesma punição não poderia ser aplicada a ambos os tipos de impiedade. Para o ateu justo, cujo único perigo é que seu pensamento atraia outros, caberia cinco anos de prisão em um centro correcional e algumas reprimendas. Se fosse reformado, poderá retornar à cidade e, caso não fosse, será punido com pena de morte.

Entre os hipócritas que afirmassem acreditar em deuses preguiçosos, irresponsáveis ou subornáveis, afirma-se que frequentemente surgiriam demagogos, tiranos e sofistas. Eles seriam dignos não de uma ou duas mortes, mas de muitas mais, se possivel. Assim, eles ficariam presos pelo resto da vida em uma prisão do interior, no lugar mais deserto e selvagem do país. Quando morressem, seus corpos seriam lançados sem sepultura para além das fronteiras da cidade. Como prevenção contra a impiedade, o ateniense acaba proibin- 
do qualquer tipo de oferendas e sacrificios em templos particulares. Todos os ritos religiosos ficariam nas mãos dos sacerdotes e sacerdotisas oficiais e seria preciso conter todos os tipos de superstições que surgiriam facilmente. Aqueles que desobedecem a essa lei proposta seria punido com a morte se desafiassem a ordem religiosa comum com suas práticas (SILVA, 2016).

\section{Considerações finais}

A religiosidade é essencial para Platão na organização geral da cidade. Desde as primeiras linhas de As Leis, o filósofo afirma que a divindade (e não os homens) é a medida de todas as coisas. Como indicado neste diálogo, a piedade constitui uma virtude prática fundamental para a organização da cidade, visto que o bom funcionamento da sociedade, bem como o exercício político, dependerá de servir aos deuses, respeitando-os e considerando-os tanto a origem como o modelo das demais virtudes. A maldade será, portanto, uma das ofensas mais graves da cidade e aqueles que acreditam que deuses não existem ou que é fácil persuadi-los com sacrifícios serão severamente punidos.

Nenhum conjunto normativo poderá ter algum sentido se a conduta humana não se aperfeiçoa em um cenário social, político e até mesmo cósmico, caracterizado pela permanência e regularidade, que apenas as divindades podem assegurar. Então, para Platão, a impiedade e o desrespeito às leis equiparam-se. A piedade beneficia o cumprimento das leis, ao passo que a impiedade contesta a própria essência de toda a coleção legislativa.

As Leis podem ser entendidas como um complemento aos programas políticos delineados nos últimos diálogos apresentados por Platão, embora em alguns momentos pareça que os renegue. Há um consenso geral de que As Leis marca a politização da filosofia política de Platão. Tudo indica que, nesse diálogo, Platão desloca seu interesse por modelos políticos ideais ou utópicos para modelos legislativos verdadeiramente viáveis. No entanto, esse deslocamento não é facilmente detectável e, nesse sentido, em As Leis persiste certa tensão entre o divino e o humano: Platão tenta articular essas duas dimensões.

Assim, longe de suscitar uma antinomia ou uma oposição, Platão busca uma forma de harmonizar o caráter divino com o racional da lei e, para cumprir esse propósito, As Leis é indispensável. Isto porque justamente nesse diálogo se destaca a necessidade de colocar a obra legislativa sob a custódia divina e, ao mesmo tempo, se mostram os limites de uma concepção fixa e estável do direito. Se Platão afirma que o verdadeiro deus deve ser o dono de homens sensiveis e com inteligência, o legislador imita a ordem cosmológica com o intuito de reproduzi-la e, ao fazê-lo, lança mão do único elemento que se assemelha ao divino, a saber, seu intelecto.

\section{Referências}

BALLÉN, Rafael. La estrutura del Estado em Las Leyes de Platón. Diálogos de Saberes, Bogotá, n. 26, p. 45-69, jan./jun. 2007. Disponivel em: https://dialnet.unirioja.es/ descarga/articulo/2693610.pdf. Acesso em: 19 jul. 2021.

BENOIT, Alcides Hector Rodriguez. A dialética hegeliana como superação da dialética platônica. Idéias, Campinas, v. 1, n. 1, p. 81/111, jan./jun. 1994. Disponivel em: https://www.ifch.unicamp.br/publicacoes/pf-publicacoes/ideias_1-1.pdf. Acesso em: 20 jul. 2021.

BRISSON, Luc. A religião como fundamento da reflexão filosófica e como meio de ação política nas Leis de Platão. Kriterion, Belo Horizonte, v. 44, n. 107, p. 24-38, jun. 2003. Disponivel em: https://www.scielo.br/j/kr/a/ PxqKdCz9Vc5VBR3b9MD3ddj/?lang=pt\&format=pdf. Acesso em: 19 jul. 2021.

DIÉS, Auguste. Notice. In: CHAMBRY, Emile. Platon. La République. Paris: Les Belles Lettres, 1947.

MOURA, Alessandro Rolim de. A poesia em Platão: a República e as Leis. Letras Clássicas, São Paulo, n. 2, p. 201-217, out. 1998. Disponivel em: https://www.revistas. usp.br/letrasclassicas/article/view/73738/77404. Acesso em: 20 jul. 2021

NADDAF, Gérard. Commentaire du livre $X$ des Lois de Platon. Annuaires de l'École pratique des hautes études, Paris, n. 89, p. 601-603, 1980-1981. Disponivel em: https://www.persee.fr/doc/ephe_0000-0002_1980_ num_93_89_18355. Acesso em: 20 jul. 2021.

OLIVEIRA, Richard Romeiro. Política, Teologia e Filosofia nas Leis de Platão. Sintese - Rev. de Filosofia, Belo Horizonte, v. 34, n. 1.10, p. 335-361, jan. 2007. Disponivel em: https://faje.edu.br/periodicos/index.php/Sintese/ article/view/162/287. Acesso em: 20 jul. 2021. 
OLIVEIRA, Richard Romeiro. Demiurgia politica: as relações entre a razão e a Cidade nas Leis de Platão. 2006. 310 p. Tese (Doutorado em Filosofia) - Universidade Federal de Minas Gerais (UFMG), Belo Horizonte, 2006.

PLATÃo. As Leis. Tradução de Edson Bini. Bauru: Edipro, 2021.

REIS, Maria Dulce. Por uma nova interpretação das doutrinas escritas: a filosofia de Platão é triádica. Kriterion, Belo Horizonte, v. 48, n. 116, p. 379-398, dez. 2007. Disponivel em: https://www.scielo.br/j/kr/a/ GC6Xd6LXShQbQKGnGXXh8XR/?format=pdf\&lang=pt. Acesso em: 20 jul. 2021.

SILVA, Felipe Gustavo Soares da. A critica ao ateísmo nas leis de Platão. Clareira: Revista de Filosofia da Região Amazônica, Porto Velho, v. 3, n. 1, p. 208-223, jan./jul. 2016. Disponível em: https://periodicos.unir.br/ index.php/clareira/article/view/3622/2502. Acesso em: 19 jul. 2021.

\section{Claudio De Cicco}

Doutor em Direito pela Pontifícia Universidade Católica de São Paulo (PUC-SP), em São Paulo, SP, Brasil. Livre docente em Direito pela Pontifícia Universidade Católica de São Paulo (PUC-SP), em São Paulo, SP, Brasil. Professor da graduação e do Programa de Estudos Pós-Graduados em Direito (PPGD) da Pontificia Universidade Católica de São Paulo (PUC-SP), em São Paulo, SP, Brasil.

\footnotetext{
Alvaro Luiz Travassos de Azevedo Gonzaga

Doutor em Filosofia do Direito e do Estado pela Pontifícia Universidade Católica de São Paulo (PUC-SP), em São Paulo, SP, Brasil. Professor da graduação e do Programa de Estudos Pós-Graduados em Direito (PPGD) da Pontifícia Universidade Católica de São Paulo (PUC-SP), em São Paulo, SP, Brasil.
}

\section{Felipe Labruna}

Graduado em Direito pela Pontifícia Universidade Católica de São Paulo (PUC-SP), em São Paulo, SP, Brasil; mestrando em Direito pela Pontifícia Universidade Católica de São Paulo (PUC-SP), em São Paulo, SP, Brasil.

\section{Endereço para correspondência}

\section{Alvaro Luiz Travassos de Azevedo Gonzaga}

Pontifícia Universidade Católica de São Paulo

Faculdade de Direito

Rua Monte Alegre, 984

Perdizes, 05014-901

São Paulo, SP, Brasil

Os textos deste artigo foram revisados pela Poá Comunicação e submetidos para validação do(s) autor(es) antes da publicação. 